\title{
TELA PLURAL? CULTURA NA TELEVISÃO BRASILEIRA
}

\section{SCREENING DIVERSITY? ON BRAZILIAN TELEVISION CULTURE}

\author{
Ana Luiza Coiro Moraes ${ }^{1}$; Ana Luiza Fleck Saibro ${ }^{2}$
}

Resumo: O presente artigo tem como pressuposto que os conteúdos produzidos e veiculados pela televisão aberta refletem o modelo de comunicação implantado no País. De fato, um olhar sobre as grades de programação das emissoras públicas e privadas mostra que as estratégias para atingir a audiência obedecem a objetivos e interesses distintos. Com base em pesquisa bibliográfica, tomada como recurso metodológico, o artigo demonstra que a programação presente nas telas da TV brasileira mostra padrão cultural diferenciado, congruente com a modalidade de serviço de radiodifusão considerado: cultura de massas nas telas das TVs comerciais e cultura de "elite" e popular nas telas das TVs públicas. Também identifica, não apenas distinções gerais entre programas "culturais" e "comerciais", mas a presença de uma noção cultural "estabelecida" igualmente importante em cada tipo de programação.

Palavras-chave: Televisão; Cultura; Programação; Emissoras Comerciais; Emissoras Públicas.

Abstract: This article assumes that the content produced and broadcast by open television reflects the communication model implemented in the country. In fact, a look at the schedules of public and private broadcasters shows that the strategies to reach the audience obey distinct objectives interests. Based on bibliographical research, taken as a methodological resource, the article demonstrates that the programming present on the Brazilian TV screens shows a differentiated cultural pattern, congruent with the mode of broadcasting service considered: mass culture in commercial TV screens and elite and popular culture on public TV screens. It also identifies not only general distinctions between "cultural" and "commercial" programs, but the presence of an "established" cultural notion equally important in each type of programming.

Keywords: Television; Culture; Programming; Commercial Broadcasters; Public Broadcasters.

\footnotetext{
${ }^{1}$ Doutora em Comunicação Social pela Pontifícia Universidade Católica do Rio Grande do Sul, com pósdoutorado em Comunicação e Cultura pela Universidade Federal da Bahia. Professora do Programa de Pós-Graduação em Comunicação da Faculdade Cásper Líbero. E-mail: anacoiro@gmail.com / alcmoraes@casperlibero.edu.br.

2 Jornalista, Mestranda em Comunicação na Faculdade Cásper Líbero e Pesquisadora do Grupo de Pesquisa Estudos Culturais na Comunicação Contemporânea (ECCC); e-mail: anaflecksaibro@gmail.com.
} 


\section{Introdução}

À primeira vista, a pertinência deste artigo pode ser questionada por aparentemente trazer à discussão ideias ultrapassadas, anacrônicas, ou "fora do lugar"3. $\mathrm{Na}$ era da cibercultura, da internet, da conectividade, da interatividade, por que e para quê estudar a televisão aberta? ${ }^{4}$ Afinal, a TV, como a conhecemos, parece estar desaparecendo.

No entanto, embora transformada para readequar seus fluxos de conteúdo às mais modernas tecnologias e à nova realidade de demandas e mudança de hábitos de consumo audiovisual por parte da audiência, a televisão aberta continua a ser o meio mais poderoso em termos de penetração no País. De acordo com a última Pesquisa Nacional por Amostragem de Domicílios (PNAD) ${ }^{5}$, dos 69,3 milhões de domicílios particulares permanentes no Brasil, apenas 2,8\%, ou 1,9 milhão, não tinham televisão. Acrescente-se o hábito de consumo regular do veículo, que é de 95\%, e de consumo diário, que chega a 73\%, ${ }^{6}$ para caracterizá-lo como meio de comunicação hegemônico.

Por outro lado, a $\operatorname{PNAD}^{7}$ também revela que 63,4 milhões de brasileiros não têm acesso à internet, seja na modalidade banda larga, fixa ou móvel. Isto significa que quase $1 / 3$ da população está excluído dos benefícios prometidos pelas novas mídias, quer por motivos econômico/financeiros, quer por analfabetismo digital, isto é, por desconhecimento de como usar os equipamentos. Por isso mesmo, o caráter gratuito do acesso à televisão aberta e o fato de penetrar em todas as classes sociais a tornou "o recurso mais importante e fonte de referência para o consumo cultural, pois é nela que se tornam públicos os fatos" no Brasil. (BACCEGA, 2000, p.103)

Mas como se dá esse movimento contínuo de troca de significados entre produtores e consumidores mediado pela televisão comercial? Que lugar estratégico a televisão ocupa nas dinâmicas da cultura cotidiana?

De outra parte, o compromisso com as possibilidades de ampliação da cidadania mediante a abertura de sua tela para a divulgação da diversidade de opiniões e

\footnotetext{
${ }^{3}$ Expressão formulada por Roberto Schwarz a respeito do liberalismo no Brasil.

${ }^{4}$ Para fins do presente trabalho, consideramos televisão aberta as emissoras que transmitem em VHF e em UHF.

${ }^{5}$ Pesquisa Nacional por Amostra de Domicílios (PNAD) realizada no último trimestre de 2016.

${ }^{6}$ Pesquisa Brasileira de Mídia 2015: hábitos de consumo de mídia da população brasileira- Secretaria de Comunicação da Presidência da República.

${ }^{7}$ Pesquisa Nacional por Amostra de Domicílios (PNAD) realizada no último trimestre de 2016.
} 
identidades vem sendo cumprido pela TV Pública? Há espaço para a veiculação de formas e manifestações culturais ausentes das telas comerciais?

Afinal, a que tipo de conteúdo os telespectadores brasileiros estão expostos?

Este artigo tem como pressuposto que os conteúdos produzidos e veiculados pela televisão aberta refletem o modelo de comunicação implantado no País: regulamentação e controle das frequências eletromagnéticas nas mãos do Estado, concessões distribuídas para exploração privada sob forte influência de interesses políticos, e uma participação marginal de emissoras educativas que, com raríssimas exceções, se transformaram em meros veículos de propaganda dos governos estaduais. Apenas em 2007, a criação da Empresa Brasil de Comunicação (EBC), gestora do sistema público de radiodifusão, significou a possibilidade de um ecossistema de radiodifusão mais equilibrado.

Com estratégias diferenciadas de comunicabilidade com a audiência, temos, portanto, de um lado, a TV privada, com gestão comercial alicerçada na publicidade, sempre regulada pela necessidade de reduzir custos e ampliar lucros. De outro, TVs educativas criadas pelos governos autoritários com o objetivo principal da transmissão de conhecimentos dirigidos e a disseminação da ideologia militar, mais tarde transformadas em veículos de propaganda dos governos estaduais. E a TV pública, ainda sem uma identidade própria, objeto de ingerências governamentais e crônicas dificuldades de financiamento.

Um olhar sobre as grades de programação das emissoras poderá nos mostrar aspectos significativos a respeito dos usos da televisão em diferentes tipos de instituição de radiodifusão. A hipótese deste artigo é que a programação presente nas telas da TV brasileira mostra padrão cultural diferenciado, congruente com a modalidade de serviço de radiodifusão considerado: cultura de massas na tela da TV comercial, e cultura erudita e popular na tela da TV pública.

Para testar nossa hipótese, examinaremos as estratégias de programação em emissoras privadas e públicas, e procuraremos evidenciar os efeitos dessas práticas nos conteúdos veiculados. Também deveremos ser capazes de identificar não apenas distinções gerais entre programas "culturais" e "comerciais", mas também a presença de uma noção cultural "estabelecida" igualmente importante em cada tipo de programação. (WILLIAMS, 2016 [1974], p. 96). 
Como será percebido ao longo do trabalho, o exame das estratégias de programação da TV comercial merecerá atenção mais destacada, o que pode ser explicado por dois motivos fundamentais. Em primeiro lugar, a presença hegemônica dos veículos comerciais no País faz com que o modelo de programação que entra nas casas dos brasileiros tenha características predominantemente "comerciais". Em segundo, porque as estratégias de programação das emissoras públicas, ou o perfil dessas programações, ainda são o nó górdio das discussões em torno do tema. Embora seja possível identificar algumas tendências, que nos permitirão testar nossa hipótese, uma análise mais aprofundada da programação de emissoras públicas deverá ensejar reflexões mais amadurecidas em outros momentos.

Com base em pesquisa bibliográfica, tomada como recurso metodológico, desenvolveremos nosso percurso tendo como fio condutor as contribuições de Raymond Williams em seus estudos sobre televisão, especialmente na obra Televisão: tecnologia e forma cultural (2016 [1974]). Também traremos aportes de autores com reflexões importantes sobre o tema televisão e cultura, especialmente Martín-Barbero (2015 [1987]), Lúcia Santaella (2003), Itânia Gomes (2002, 2011) e François Jost (2007). Teresa Otondo (2012), Eugênio Bucci (2009), Valerio Fuenzalida (2002) e Orozco Gomes (2002), darão suporte a nossas reflexões a respeito das emissoras públicas.

Para organizar a discussão, o artigo está dividido em três partes, além desta introdução e das considerações finais. A primeira discute teoricamente a programação de TV como fluxo contínuo e tenta identificar as estratégias utilizadas pelos programadores para atingir a audiência. $\mathrm{Na}$ sequência, apresentamos um perfil da trajetória da televisão comercial brasileira, as particularidades que caracterizam o modelo, e tentamos demonstrar a aplicabilidade das discussões teóricas anteriores na prática.

Na terceira parte, discutimos a relação televisão e cultura de modo a confirmar a hipótese proposta por este artigo. Nas considerações finais, fazemos um breve resumo do que foi discutido e vislumbramos a necessidade de um maior esforço de análise a respeito das estratégias de programação das emissoras públicas em um futuro trabalho.

\section{Programação: relações discursivas entre produtores televisivos e telespectadores}

A compreensão acerca da natureza do fluxo de informações no processo comunicativo é condição indispensável para uma análise da cultura e dos meios 
massivos, em especial a televisão. Esta tarefa, acreditamos, como sugere MartínBarbero em seu livro Dos Meios e Mediações: Comunicação, Cultura e Hegemonia (2015 [1987]) deve vincular a relação emissor-mensagem-receptor ao contexto histórico, econômico, social e cultural em que ocorre. Especificamente em relação à televisão, convém observar os conteúdos, não de forma descontextualizada, mas compreender as próprias dinâmicas e processos que integram os programas, gêneros e formatos, e como são compreendidos pelo telespectador.

Ao longo de sua trajetória, a televisão tem desenvolvido formas específicas de narrativa e organização. Segundo Raymond Williams (2016 [1974]) a televisão não é estruturada em unidades separadas, nem dividida entre programas e anúncios publicitários. Em vez disso, se caracteriza pelo fluxo contínuo e planejado de imagens e sons, "em que a verdadeira série não é a sequência publicada de programas, mas essa sequência transformada pela inclusão de outro tipo de sequência, de modo de que essas sequências juntas compõem o fluxo real, a real 'radiodifusão"'. (WILLIAMS, 2016 [1974]), p. 100).

Conforme entende o autor britânico, em todos os sistemas de radiodifusão desenvolvidos, a organização característica - logo, também a experiência característica - é a da sequência ou fluxo. Deste modo, esse fenômeno de um fluxo planejado talvez seja, segundo ele, a característica que define a radiodifusão simultaneamente como uma tecnologia e uma forma cultural.

Além disso, Williams assinala que em todos os sistemas de comunicação anteriores à radiodifusão os elementos essenciais estavam separados. Por exemplo, um livro ou um panfleto eram lidos como um item específico. Uma peça era encenada em um teatro específico, em determinada hora. A diferença na radiodifusão, afirma, não é apenas que o fluxo de programação está disponível no lar, ao simples ligar de um aparelho. "Mas, sim, que o programa de fato oferecido é uma sequência ou um conjunto de sequências alternativas desses ou de outros eventos similares, que assim ficam disponíveis numa única dimensão e numa única operação” (WILLIAMS, 2016 [1974]), p.96-97).

Neste processo, os programas se sucedem de modo a "capturar" a atenção do espectador e a "retê-la" durante toda a sequência, programa após programa, inclusive por meio de trailers sobre a programação a seguir. De acordo com o autor, a maneira 
como o fluxo está organizado tem relação com a própria experiência televisiva. Por exemplo, ao descrevermos esta experiência, a maioria de nós diz que está "assistindo à televisão", não a um programa específico. Por isso mesmo, achamos bastante difícil desligar a televisão; "várias vezes, mesmo quando ligamos a televisão para assistir determinado programa, pegamo-nos assistindo à atração que vem depois e a seguinte (WILLIAMS, 2016 [1974], p. 103). Na verdade, o fluxo é planejado para prender nossa atenção nos momentos iniciais do programa e "prometer reiteradamente que coisas excitantes estão por vir, se permanecermos assistindo" (WILLIAMS, 2016 [1974], p. 104). Essa regularidade de exibição dos programas com um ordenamento sequencial previsível, permite uma identificação do telespectador com determinada estrutura narrativa que faça sentido dentro de sua competência cultural. Assim, há também um fluxo de significados e valores de uma cultura específica no fluxo televisivo.

Neste ponto, é importante destacar que a ideia de fluxo televisivo proposta por Williams nos anos 1970, embora referência na análise dos aspectos mais gerais da dinâmica interna da televisão, tem sido questionada em vista do surgimento de outras plataformas de mídia que trazem consigo novas formas de fazer e de assistir televisão, e que teriam tomado o lugar da radiodifusão. No entanto, no Brasil, com a TV aberta como veículo amplamente hegemônico, o modelo centrado na grade de programação ainda é reconhecido como o responsável pela organização da experiência audiovisual. Portanto, conceitos como horizontalidade e verticalidade na organização dos programas ainda nos parecem válidos e oportunos para a análise a que nos propomos. Em que pesem os questionamentos acerca do broadcasting, o sistema tradicional ainda se mantém importante na experiência televisiva brasileira.

Martín-Barbero (2015 [1987]) e Itânia Gomes (2002, 2011) agregam conceitos fundamentais à esta discussão sobre a natureza das relações discursivas entre produtores televisivos e os telespectadores. O autor parte da premissa de que a dinâmica cultural da televisão atua pelos seus gêneros; e, que “...os gêneros constituem uma mediação fundamental entre as lógicas do sistema produtivo e as do sistema de consumo, entre a do formato e a dos modos de ler, dos usos". (MARTÍN-BARBERO, 2015 [1987], p. 300-301). Assim, do ponto de vista dos produtores/emissores, os gêneros atuam como estratégia de comunicabilidade, de interação com o público. Para a audiência, completa 
Gomes (2002), "os gêneros funcionam como uma espécie de manual de uso" dos produtos televisivos (GOMES, 2002, p. 182).

Mais especificamente, a autora entende que gênero é um modo de situar a audiência televisiva em relação a um programa, em relação ao assunto nele tratado e em relação ao modo como o programa se destina ao seu público. Por isso mesmo, considera que a adoção do conceito de gênero televisivo possibilita ao analista o reconhecimento da existência de relações sociais e históricas entre determinadas formas culturais e as sociedades e períodos nos quais essas formas são praticadas.

Já o conceito de modo de endereçamento, também trazido pela autora, na perspectiva da análise televisiva se refere a como um determinado programa se relaciona com sua audiência a partir da construção de um estilo, que o identifica e que o diferencia dos demais. Em outras palavras, é utilizado "para compreender a relação de interdependência entre emissores e receptores na construção de sentido do texto televisivo" (GOMES, 2011, p. 34).

Não há como ignorar que os gêneros e modos de endereçamento dos emissores estão vinculados (ou dependem) à estrutura comercial de uma emissora ou produtora de televisão. Por isso mesmo, como entende Martín-Barbero (2015 [1987], é preciso verificar "o que da estrutura produtiva deixa vestígios no formato, e os modos com que o sistema produtivo - a indústria televisiva - semantiza e recicla as demandas oriundas dos 'públicos' e seus diferentes usos” (MARTÍN-BARBERO, 2015 [1987], p. 301). Estão incluídos entre os fatores que deixam esses "rastros" a competitividade industrial, as ideologias profissionais, as rotinas de produção e, principalmente, as estratégias de comercialização.

De fato, um olhar sobre as lógicas de programação das emissoras de televisão comerciais permite constatar a falta de neutralidade que permeia as decisões dos produtores televisivos, com reflexos inegáveis sobre a natureza do conteúdo veiculado. Como alerta Jost (2007), nada na programação de uma emissora é definido de maneira aleatória. É a partir da programação que emana o significado da mensagem televisiva, pois

[...] escolher conteúdos e colocá-los em faixas horárias, ação entendida como arte de programar, não é um procedimento neutro. A seleção, como a sucessão e a aproximação dos programas são criadores de sentido e contribuem para forjar a identidade da emissora (Jost, 2007, p. 52). 
A experiência da televisão comercial brasileira, apresentada a seguir, nos permite observar como se processam, na prática, estas estratégias de programação.

\section{Televisão comercial à brasileira}

A partir dos anos 1970, o desenvolvimento técnico-industrial da televisão comercial brasileira gerou uma centralização da produção no Sudeste, especialmente Rio de Janeiro e São Paulo, e a consequente hegemonia cultural da região. A estruturação do sistema de radiodifusão em redes nacionais, ao mesmo tempo em que oportunizou a construção de uma "identidade nacional", dentro da lógica dos governos militares, relegou a difusão autônoma da cultura regional e local a segundo plano. Olhares independentes e visões diferentes praticamente ficaram de fora das telas de nossa televisão. A fragilidade econômica do mercado anunciante na maioria das praças fora do eixo Rio-São Paulo levou a uma situação em que as emissoras locais e regionais se converteram, praticamente, em meras repetidoras das redes nacionais, veiculando um número irrelevante de programas próprios.

Apesar da diversidade cultural e da pluralidade de vozes existentes em um país de dimensões continentais e dos vários formatos e experiências possíveis de serem testados, o que se passou a ver na TV aberta, com raras exceções, foi uma maioria absoluta de conteúdos - ficcionais ou jornalísticos - abordando ou se baseando na realidade do Sudeste.

A "identidade nacional ", portanto, ou a visão que os brasileiros têm de si mesmos e do país, passou a ser mediada fortemente pelo ponto de vista das duas maiores metrópoles. Consolidou-se a ideia de um centro dinâmico, avançado e cosmopolita - o eixo Rio-São Paulo - em contraste com uma periferia atrasada, conservadora e provinciana (BORELLI e PRIOLLI, 2000, p. 19).

Além disso, os crescentes custos de produção de programas consolidaram a tendência à integração vertical entre os segmentos de produção e veiculação de conteúdo. No Brasil, os diferentes elos da cadeia produtiva do setor do audiovisual (produção, programação, empacotamento e distribuição) são desenvolvidos pela mesma organização. As emissoras geradoras de televisão aberta ao mesmo tempo produzem, programam e distribuem os próprios conteúdos.

Essa valorização da racionalidade gerencial e da otimização comercial trouxe consigo a ideia da construção de uma programação homogênea voltada para um público médio, com base nos conceitos da horizontalidade e a verticalidade na organização dos 
programas televisivos. Por horizontalidade entenda-se a colocação de um programa ao longo da semana ou do mês, em um mesmo horário. Verticalidade é a sequência ao longo do dia que vai sendo repetida semana a semana, mês a mês.

Premidas pelos índices de audiência, que significam verbas publicitárias, o desafio das emissoras é alcançar um público difuso, indeterminado, desde que seja o mais numeroso possível. A estratégia foi sempre a de criar uma segmentação por horários específicos. Assim, por exemplo, as manhãs foram durante muito tempo reservadas aos programas infantis ${ }^{8} \mathrm{e}$ as tardes, tradicionalmente dedicadas aos chamados programas femininos. O final da tarde apresenta programas que fazem "escada" para a chamada prime time, no início da noite, horário tradicionalmente de maior audiência na TV aberta. Os programas voltados para as classes mais altas, sem apelo popular, são apresentados num horário mais tardio (BORELLI e PRIOLLI, 2000).

Uma palavra sobre a relação entre televisão comercial e publicidade se faz imprescindível. Não se pode falar de uma sem a outra. O discurso de Assis Chateaubriand na solenidade de inauguração da TV Tupi de São Paulo em 1950 não deixou dúvida sobre os rumos que a TV comercial tomaria no Brasil. Por sua excentricidade (ou mesmo surrealismo) transcrevemos um pequeno trecho:

\section{Esse transmissor foi erguido com a prata da casa, isto é, com os recursos de publicidade que levantamos, sobre as Pratas Wolff e outras não menos maciças pratas da casa; a Sul América que é o que pode haver de bem brasileiro, as lãs Sams, do Moinho Santista, arrancadas ao coiro das ovelhas do Rio Grande, e mais do que tudo isso, o guaraná Champagne da Antarctica, que é a bebida dos nossos selvagens...] (ORTIZ, 1988, p. 59).}

$\mathrm{Na}$ verdade, desde o seu início a televisão brasileira se caracterizou como veículo publicitário por excelência, à semelhança do modelo americano. Nos primeiros anos, os patrocinadores determinavam os programas que deveriam ser produzidos, além de contratar diretamente os artistas e os produtores. Os programas e até mesmo os telejornais eram identificados pelo nome do patrocinador: Repórter Esso, Telenotícias Panair, Teatrinho Trol, Gincana Kibon. Claro, ao longo dos anos esta influência direta foi diminuindo, embora as grandes redes ainda contem com a participação dos profissionais das agências de publicidade para decisões estratégicas sobre horários de

\footnotetext{
${ }^{8}$ A programação infantil esteve presente na grade matinal das emissoras abertas durante muito tempo, principalmente pelo seu valor como vitrine de exposição de bens diretamente para a criança, ou indiretamente para seus familiares. No entanto, o Estatuto da Criança e do Adolescente (Lei 8.069/1990), introduziu regras com limites à publicidade infantil, o que acabou por tornar a manutenção desses programas economicamente inviável. Também o desenvolvimento da TV por assinatura significou grande concorrência ao oferecer grande diversidade de canais infantis segmentados.
} 
exibição de programas e para identificar tipos de programas mais facilmente vendidos a determinado patrocinador, por exemplo (MATTOS, 2010).

Nesta trajetória, por meio de sua programação, construída de modo a atrair e cativar a audiência (e as verbas publicitárias), a televisão comercial se incorporou à rotina doméstica, tornou-se íntima dentro dos lares, e se transformou para atender às demandas socioculturais da audiência ao longo do tempo. E não deixou de lançar mão da alteração da grade de programas sempre que se viu ameaçada pela perda nos índices de audiência. Como diz Felisbela Lopes (2008), "antes de serem meios de difusão de conteúdo, os canais televisivos são empresas cujo financiamento depende do sucesso de um trabalho tributário da aceitação do público" (LOPES, 2008, p. 26).

Em suma, sempre foi o índice quantitativo da audiência, ou seja, o número de televisores ligados em um determinado canal, o que determinou e influenciou as estratégias e a tomada de decisão dos produtores televisivos. Isto com reflexos inegáveis sobre a natureza e o perfil da programação.

\section{Cultura nas telas: de massa, erudita ou popular?}

Martín-Barbero (2015 [1987]) talvez seja o autor que melhor tenha sintetizado as diferentes visões acerca da relação televisão/cultura.

Aponta, de um lado, os críticos que encaram a televisão a partir do paradigma da arte e os fatigados argumentos sobre a decadência cultural representada pela televisão. Para estes, a televisão não seria assunto de cultura, só de comunicação.

De outro lado, estão os que ele chama de os folclóricos, que situam a verdadeira cultura no povo, naquele que conserva a verdade sem contaminações ou mestiçagens e propõem tornar televisivo o patrimônio de danças e indumentárias nacionais.

Em outro eixo, há os que defendem, à moda populista, o atendimento das demandas manifestadas em pesquisas de audiência, e o setor público, falando à moda paternalista em nome das verdadeiras necessidades culturais das pessoas (MARTÍNBARBERO, (2015 [1987], p. 299).

Baccega (2000) também identifica a oposição entre visões “apocalípticas e integradas" em relação à televisão. De um lado, os que consideram os meios de comunicação os principais responsáveis pela queda de parâmetros como a ética e a instituição familiar (os apocalípticos); de outro, os que endeusam os meios de 
comunicação, atribuindo a eles o papel de sustentáculos do progresso (os integrados) (BACCEGA, 2000, p. 99).

Em linha semelhante, Felisbela Lopes (2008) reconhece a existência de modos distintos de apreensão da televisão, a partir de dois tipos de visão: crítica e integradora. Segundo a autora, "Tal como a relação que cada um dos telespectadores mantém com a programação televisiva, são múltiplas as visões que poderemos construir acerca da televisão. Depreciativas ou eufóricas. Pessimistas ou integradoras” (LOPES, 2008, p.17).

$\mathrm{Na}$ verdade, qualquer que seja o entendimento em relação ao veículo, não há como negar que são os meios de comunicação que, contemporaneamente, atribuem significado à realidade, e, no limite, conformam nossas identidades. Ou seja, a circulação dos bens simbólicos pelos meios de comunicação nos remete à noção de cultura e à identificação de um conjunto de bens culturais por eles produzidos.

Importante ressaltar que a noção de cultura se modificou gradualmente ao longo do tempo como consequência do surgimento de meios técnicos de produção cultural. Santaella (2003) explica que até a segunda metade do século XIX, não era difícil identificar as hierarquias dos estratos culturais: de um lado, os estratos eruditos, de outro, os estratos populares, tidos como alta e baixa cultura respectivamente. "As belas artes (desenho, pintura, gravura, escultura), as artes do espetáculo (música, dança, teatro) e as belas letras (literatura) [...] distinguiam-se do folclore, das formas populares de cultura" (SANTAELLA, 2003, p.55).

A partir da revolução industrial, entretanto, esse cenário foi se alterando, segundo a autora. O surgimento dos meios técnicos de produção cultural e de reprodução técnico-industriais - jornal, foto, cinema - propiciaram o surgimento da cultura de massas, intensificada pelos meios eletrônicos de difusão - rádio e televisão, o que acabou por desfazer a tradicional distinção entre cultura erudita e a cultura popular. "A cultura de massas parece absorver essas duas formas de cultura, dissolvendo essa polaridade e pondo fim às barreiras entre elas". (SANTAELLA, 2003, p. 52).

Essas análises a respeito do impacto da disseminação dos meios de comunicação sobre a noção de cultura não são novas. Adorno e Horkheimer, os pensadores da Escola de Frankfurt, em sua obra Dialética do Esclarecimento (1985 [1947]), já denunciavam que a indústria cultural promovia uma fusão da cultura erudita com a cultura popular, 
esvaziando as relações contraditórias existentes entre elas, e transformando-as em produtos de consumo.

Também o culturalista britânico Richard Hoggart, em seu livro The uses of literacy, escrito em 1957, já alertava para o fato de que a indústria do entretenimento, os modos de produção industrial e as novas tecnologias de comunicação produziam para uma nova "audiência sem classes", por simples razões mercadológicas. E considerava o mercado como a categoria capaz de atenuar as distinções entre cultura popular autêntica, erudita e de massa, mas promovendo "um tipo mais medíocre de cultura sem classe ou... uma cultura 'sem rosto"” (COIRO-MORAES, 2008, p. 28).

Esta breve revisão de autores deixa evidenciado não haver discordância em relação à natureza cultural do conteúdo veiculado pela televisão. Nos alinhamos a tais leituras, mas julgamos imperioso fazer neste ponto uma distinção fundamental. Conforme entendemos, o conceito de conteúdo massivo, ou cultura de massas, se conforma mais àquele produzido e veiculado pelas TVs comerciais e, menos, em termos gerais, ao produzido e transmitido pelas TVs de caráter público.

Embora não seja objeto deste trabalho examinar a programação específica de qualquer veículo, é possível constatar que as grades das TVs comerciais estão formatadas para atingir o telespectador médio, como já referido anteriormente. As empresas tendem a procurar o "menor denominador comum", privilegiando os programas mais populares, os mais baratos e, por conseguinte, os mais rentáveis, independentemente da sua qualidade.

Quando, por outro lado, lançamos nosso olhar para a programação das emissoras públicas, aqui especificamente a TV Cultura, de São Paulo, e a TV Brasil, gerida pela EBC, recortadas para fins deste trabalho, podemos identificar outra estratégia de comunicabilidade utilizada pelos programadores, para citar a expressão de MartínBarbero (2015 [1987]).

$\mathrm{Na}$ verdade, é sobre a própria missão de serviço público de televisão que estamos falando. Embora possamos adotar concepções e abordagens conceituais distintas sobre os atributos que definem um serviço público de rádio e televisão, parece não haver divergência a respeito de alguns requisitos mínimos que devem conformar a programação. Ela deve ser plural, diversa, inovadora e com variedade de programas com alto padrão ético e de qualidade, e que oportunize espaços para a discussão de 
temas de interesse universal; o jornalismo deve ser imparcial e independente. Com isso em mente, o que e como se programa nas televisões públicas? No caso do Brasil, verificamos dois perfis distintos de programação nas TVs públicas.

Reconhecida como alternativa de qualidade em meio à irrelevância das programações das demais TVs educativas, a TV Cultura de São Paulo tem sido muitas vezes acusada de ter um viés "elitista", com uma visão instrumental da televisão como meio de elevação do padrão cultural da audiência, a partir do referencial de produtores pertencentes à elite cultural e intelectual do País.

Eugênio Bucci, integrante do Conselho Curador da TV Cultura entre 2007 e 2010, explica, entretanto, essa necessidade de se manter uma programação cultural na TV Pública.

Uma TV comercial não pode se dar ao luxo de exibir programas de literatura ou de música clássica. Eles não dão lucro. Já a TV pública tem o dever de mantê-los na grade, pois os cidadãos que normalmente não têm acesso às salas de concerto ou aos saraus literários dependem dela para conhecer essas formas de arte (BUCCI, 2009, s/p).

De maneira semelhante, Valerio Fuenzalida (2002) afirma que a matriz da alta cultura e do debate acadêmico, onde os programas são quase todos concertos, espetáculos de danças, balé e debates de cunho científico e acadêmico é entendida como a forma mais "prestigiosa" de fazer televisão, por se acreditar que a função do meio é levar cultura à população. Com efeito, na maioria dos países da América Latina, com o modelo de comunicação similar ao do Brasil, o lugar da "alta cultura" não está coberto pelas emissoras comerciais; programas assim classificados encontram seu espaço nas telas das TVs públicas.

Entretanto, no entendimento de Orozco Gomes (2002), a televisão pública não deve ficar enclausurada em programações de "alta cultura", normalmente dirigida a públicos de elite, mas deve redimensionar os seus tratamentos televisivos para oferecer tanto "programas de arte, como qualquer outro tipo de programação (novelas, reportagens, e até reality shows, respeitosa e eticamente produzidos e transmitidos. A chave seria precisamente esta: a ética e o respeito às audiências" (OROZCO GÓMEZ, 2002, p. 259).

Além disso, em sua visão,

O espetacular deveria ser substituído pelo que é relevante culturalmente (política, educativa e socialmente) para as diferentes audiências, e evidenciando o que à primeira vista escapa ao olhar ou foi silenciado, coberto ou ficou empoeirado nas outras telas (OROZCO GÓMEZ, 2002, p. 259). 
Assim, quando difunde criações da cultura popular, "a TV pública dá visibilidade a manifestações que sem ela minguariam na escuridão" (BUCCI, 2009, $\mathrm{s} / \mathrm{p}$ ). Nesta linha, a grade de programação da TV Brasil evidencia grande preocupação em assegurar a visibilidade das manifestações culturais que representam a diversidade regional do País, em substituição às produções com sotaque do eixo rio-são Paulo presentes na programação das emissoras comerciais. Em vista da crônica escassez de recursos para produção própria e burocracia na sua gestão, o caminho encontrado foram as parcerias com outros órgãos do Governo Federal responsáveis pelas políticas públicas nas áreas de comunicação e cultura.

Especialmente por meio do programa como "Brasil de Todas as Telas", iniciativa da Agência Nacional do Cinema (Ancine), em parceria com o Ministério da Cultura (MinC), a TV Brasil destaca-se pela exibição de programação feita por produtores independentes que trazem para as telas a cultura popular regional e local de todos os cantos do País. Desta forma a produção cultural brasileira ganhou espaços impossíveis de serem alcançados dentro dos limites do mercado, imposto à mídia comercial.

Como vimos, portanto, sem as pressões dos índices de audiência, porque não sujeita aos condicionantes do mercado publicitário, a TV pública abre suas telas para realizadores independentes, valorizando a diversidade estética e cultural, o que inclui manifestações da chamada cultura erudita e da cultura popular. Já a chamada cultura de massas mostra sua face nas telas das TVs comerciais.

Convém ressaltar, por fim, que este artigo não teve como objetivo fazer uma distinção entre consumidores, construídos pela televisão comercial, e cidadãos, construídos pela televisão pública. De fato, esta diferenciação é questionável e deve ser evitada. Fuenzalida adverte que essa postura pode trazer à tona, inadvertidamente,

\begin{abstract}
a antiga ideia iluminista e marxista de que a liberdade se opõe à igualdade, $\mathrm{e}$ assim são legitimadas as ditaduras do proletariado do século XX e as monarquias do despotismo ilustrado dos séculos anteriores. Também sob essa oposição aparece o ideal ascético e monacal, segundo o qual o consumo ou gozo dos bens materiais se opõe ao cultivo do espírito; ou faz alusão à oposição entre "ser" e "ter" (FUENZALIDA, 2002, p. 335).
\end{abstract}

\title{
Considerações Finais
}

Ao longo do artigo, investigamos o movimento contínuo de significados, o fluxo constante de experiências e troca de textos e discursos entre produtores e consumidores 
mediada pela televisão. Observamos também que a programação televisiva segue um ordenamento sequencial previsível que a vincula com o telespectador, atendendo suas expectativas e disputando sua fidelização ao veículo. Em outras palavras, a regularidade na exibição dos programas permite uma identificação do telespectador com determinada estrutura narrativa que faça sentido dentro de sua competência cultural. Trata-se, portanto, de uma estratégia de comunicabilidade, espécie de pacto entre quem produz e quem recebe o conteúdo.

Também fomos capazes de constatar que estas estratégias de programação em emissoras públicas e privadas obedecem a critérios distintos, a depender da natureza cultural ou comercial de seus objetivos e interesses. De um lado, o modelo econômico da TV privada, sempre regulado pela necessidade de reduzir custos e ampliar lucros, com propósitos e finalidades bem definidas. De outro, o modelo público, ainda sem definições conclusivas sobre os critérios que devem nortear sua programação, embora existam atributos básicos relacionados com diversidade cultural, imparcialidade jornalística, políticas afirmativas e abertura de vozes às minorias, que devem estar presentes.

Este trabalho tratou de cultura. Da cultura produzida e transmitida pela televisão e recepcionada pela audiência. Gostemos ou não, para o bem ou para o mal, como diz Martín-Barbero (2015 [1987]), é a própria noção de cultura, sua significação social, o que está sendo transformado pelo que a televisão produz.

Foi possível observar que há janelas de exibição nas telas da TV brasileira para diferentes manifestações culturais, das chamadas cultura erudita e cultura popular nas emissoras públicas e da cultura de massas nas telas das TVs comerciais. O que ocorre é o imenso desequilíbrio entre a presença de um sistema comercial forte, amplamente consolidado, e um sistema público incipiente, com crônicas dificuldades de distribuição e de penetração nacional, continuamente tendo que justificar a sua existência e, em particular, os gastos de recursos públicos com as suas atividades.

O que parece ocorrer na realidade midiática do País é a ausência ou a “interdição" de ideias antagônicas, a redução do espaço de circulação de visões alternativas e de contestação, de modo a evitar expressões de dissenso, para usar o conceito de Rancière (2012). A falta de tradição da cultura brasileira com a existência de um sistema público de radiodifusão, em vista da conformação da estrutura dos meios 
de comunicação no País, faz com que os conteúdos "de massa", no sentido de homogeneizados, acabem por dominar as telas brasileiras.

Por todo o exposto neste artigo, consideramos se fazer necessária uma melhor compreensão a respeito das estratégias e objetivos, aqui inicialmente discutidos, no que se refere à programação das emissoras públicas. Na verdade, nossa hipótese inicial, para um próximo trabalho, é que essas emissoras podem atuar como instrumento de "regulação estrutural". Isto é, sua programação pode ter um "efeito de demonstração" e apontar para a possibilidade de se almejar a qualidade na televisão brasileira. Podem, na verdade, abrigar 'cenas de dissenso' ou seja, “ações de sujeitos que não eram, até então, contados como interlocutores, irrompem e provocam rupturas na unidade daquilo que é dado e na evidência do visível para desenhar uma nova topografia do possível (RANCIÈRE, apud MARQUES, 2011, p.116).

\section{Referências}

ADORNO, T. e HORKHEIMER, M. A Indústria cultural: o esclarecimento como mistificação das massas. In: Dialética do Esclarecimento. Rio de Janeiro: Zahar, 1985 [1947], p.112 a 156.

BORELLI, S. H. S. \& PRIOLLI, G. (Coord.). A deusa ferida: porque a Rede Globo não é mais a campeã absoluta de audiência. São Paulo: Summus, 2000.

BACCEGA, Maria Aparecida. Comunicação/Educação: aproximações. In: A TV aos 50: criticando a televisão brasileira no seu cinqüentenário. São Paulo: Fundação Perseu Abramo, 2000, p. 95-109.

BUCCI, Eugênio. Audiência em tv pública. O Estado de São Paulo, São Paulo, 26 mar. 2009. Opinião.

COIRO MORAES, Ana Luiza. A síndrome do protagonista: uma abordagem cultural às personagens dos espetáculos de realidade da mídia. 2008. $319 \mathrm{f}$. Tese (Doutorado) - Curso de Comunicação Social, Pucrs, Porto Alegre, 2008. Cap. 2. Disponível em: $<$ http://tede.pucrs.br/tde_busca/arquivo.php?codArquivo=1291>. Acesso em: 25 abr. 2017

FUENZALIDA, Valério. Programação: por uma televisão pública para a América Latina. In: Televisão pública: do consumidor ao cidadão. RINCÓN, Omar (Org.). Quito: Friedrich Ebert Siftung, 2002, p. 155-200.

GOMES, Itânia. M. M. A noção de gênero televisivo como estratégia de interação: o diálogo entre os cultural studies e os estudos da linguagem. Revista Fronteiras: estudos midiáticos. São Leopoldo: UNISINOS, v. 4, nº 2, 2002, p. 165-185.

GOMES, Itânia. Metodologia de análise no telejornalismo. In: GOMES, Itânia (Org.) Gêneros televisivos e modos de endereçamento no telejornalismo. Salvador, Edufba, 2011, p. 17-37.

JOST, François. Compreender a televisão. Porto Alegre: Sulina, 2007.

LOPES, Felisbela. A tv do real. A televisão e o espaço público. Coimbra: MinervaCoimbra, 2008. 
MARQUES, Ângela Cristina Salgueiro. Relações entre comunicação, estética e política: tensões entre as abordagens de Habermas e Rancière. Revista Compolítica, n. 2, vol. 1, ed. set-out, ano 2011, p. 110-130.

MARTÍN-BARBERO, Jesús. Dos meios às mediações - comunicação, cultura e hegemonia. Rio de Janeiro: UFRJ, $7^{\mathrm{a}}$ ed., 2015 [1987].

MATTOS, Sérgio. História da televisão brasileira: uma visão econômica, social e política. Petrópolis: Vozes, 5 ed. rev. e ampl. 2010.

ORTIZ, Renato. A moderna tradição brasileira. São Paulo: Brasiliense, 2006.

OROZCO GOMEZ. Mediações e televisão pública: a desconstrução múltipla da televidência na era da vassalagem mediática. In: In: Televisão pública: do consumidor ao cidadão. RINCÓN, Omar (Org.). Quito: Friedrich Ebert Siftung, 2002, p. 233-266.

OTONDO, Teresa. Televisão pública. Para quem e para quê? São Paulo: Annablume, 2012.

RANCIÈRE, J. O espectador emancipado. São Paulo: Martins Fontes, 2012.

SANTAELLA, Lucia. Culturas e artes do pós-humano: da cultura das mídias à cibercultura. São Paulo: Paulus, 2003.

WILLIAMS, Raymond. Televisão: tecnologia e forma cultural. Belo Horizonte: PUC Minas, 2016 [1974]. 